\title{
Social Technology Enhancing the Town Centre Management Attractiveness
}

\author{
Federica Caboni ${ }^{1^{*}}$, Roberto Bruni ${ }^{2}$
}

\begin{abstract}
The article describes the social technology's role in the TCM attractiveness from the retailers' perspective. The exploratory research experience in Sweden during different periods between 2012 and 2016 includes contributions of the literature, direct interviews and analysis of the TCM's websites. The state-of-the-art of social commerce perception by managers and retailers is defined, and specific evidences are given through research. An interpretation of the concept of attractiveness of the TCM is presented to explain how social commerce could affect this property. Dissonance between opinions and statements of TCM stakeholders are discussed, and the will to use social commerce to increase opportunities for TCM is, in general, declared by retailers, but it is not realized in practice in management activities. A comparative empirical exploration between different countries could be conducted in future. This paper explores the actual situation in the use of website sustaining that the social commerce and the social networks are able to go beyond the supporting of commerce activity and they are able to support the TCM attractiveness and place attachment.
\end{abstract}

Keywords: Town Centre Management; social commerce; attractiveness; belonging

Submitted: January $7^{\text {th }}, 2018$ / Approved: April $6^{\text {th }}, 2018$

\section{Introduction}

This work integrates the literature on marketing and management of places with a particular focus on Town Centre Management (TCM). The work is centred on the use of social technology to improve the relationships between stakeholders and the value offered by the place. A particular research focus is on the role of users, actors, and stakeholders with regards to their involvement in social network activities, and this study investigates-with literature and specific observation experiences-the perceived and effective role of social commerce in TCM activities. Different actors argue that the mix of hard and soft conditions is relevant in territorial development. In a place-marketing approach, Musterd and Murie (2010) state that within four relevant theoretical frameworks, relationships and hard and soft conditions are at the base of territorial development, and they assume that technology and innovation are between the relevant assets in territorial development. Different perspectives include research over technology, ICT, and innovation about places. Also, the open innovation in relation to the territory development is increasing in relevance (Baron et al. 2016), and SMART city projects (Shapiro, 2006; Caragliu et al. 2011; Chourabi et al. 2012) contributes different points of view and specializations. The research paths are addressed toward the study of relations between technology and human interactions that increase the quality of life through participation. Value-exchange technology becomes part of the place, and the concept of "connection" multiplies the opportunities and will to be part of the system of values. In that context, the Internet is a fundamental source of relationships and connections and could contribute to improving the quality of life in a city. Coca-Stefaniak (2014) and (Caboni and Bruni 2015) suggest to concentrate efforts on the study of relationships between TCM, new technologies, and social networks. Also, new research activities could contribute to increase the efforts in public-private activities, which merge different contributions between place stakeholders and the meaning behind the multiplicity of an organizational model. This work is focused on the scenario of a TCM and on the perspective of TCM attractiveness with respect to its stakeholders. The concept of attractiveness is now explained. In particular, there is a rule of "belonging" for a subject to be involved with a TCM as a property of stakeholders involved in TCM caused by the system of stimuli generated by offline (asset and driver of the place) and on line activities (the online sharing activity and the social web to express their opinion the social commerce as stimulator of belonging). New challenges have affected town centre management. In particular, the development of new technologies through the Internet such as social media has improved visitor experiences by linking the virtual and physical world (Caboni and Bruni, 2015; Coca-Stefaniak, 2014). The development of social and innovation technologies (Coca-Stefaniak, 2014) give to customers new tools to manage their shopping activities and to increase their shopping experience as well as their relationship with the city. Today, the development of the Internet and social technology (e.g., social commerce) has changed and continues to change the behaviour of town centre retailers with regards to managing their activities (Rezaei and Ismail, 2014; Chang, 2012; Izquierdo-Yusta and Newell, 2011). These technologies can be used with planned initiatives to completely revitalize the town centre's vitality. Also, social media now puts enormous pressure on traditional retailers. In this scenario, it is important to understand in what way the use of social commerce is perceived by Town Centre retailers. Is it only a significant element to increase their single business or could it be useful to increase the town centre attractiveness and consequently attract new interest in this urban area? In the second stage of this study, we present an analysis of the multifaceted characteristics that compose social commerce, and we particularly emphasize how this can be applied to town centre permits to revitalize the town centre. The article is organized as follows. First, the theoretical background of the topic is discussed, and we present an overview of the social changes apparent

(1) Department of Economic and Business Science, University of Cagliari, Via S. Ignazio 17, 09123, Cagliari, Italy.

(2) Department of Economics and Law, University of Cassino and Southern Lazio, Viale dell'Università, 03043, Cassino, Italy.

*Corresponding author: federica.caboni@unica.it 
within the city centres. Also, the TCM scheme and the social commerce in the context of the TCM are discussed. The work continues by outlining the methodology and the field analysis. The article ends by highlighting the role of social commerce in relation to the retailers and TCM with a special focus on the role of s-commerce and the sense of belonging to TCM.

\section{Theoretical Background}

A brief theoretical background is presented to identify new challenges have affected town centre management. In particular, the development of new technologies through the Internet such as social media has improved visitor experiences by linking the virtual and physical world (Caboni and Bruni, 2015; Coca-Stefaniak, 2014). The development of social technologies (Coca-Stefaniak, 2014) give to customers new tools to manage their shopping activities and to increase their shopping experience as well as their relationship with the city.

\section{The social commerce: toward the TCM contextualization}

Social commerce (s-commerce) is considered as a commerce activity developed through social media, such as Facebook, Twitter, or other platforms (Ickler et al., 2009; Liang, et al., 2011; Liang and Turban, 2011), where people have the possibility to share their purchases with other people that populate the virtual world; in this way, these technologies attempt to enhance shopping experiences in a shared online environment (Curty and Zhang, 2011). Several scholars defined s-commerce as a new form of Internet sales developed in the last ten years (Curty and Zhang, 2011; Roblek et al., 2013). In 2005, Yahoo! introduced the concept of s-commerce (Jascanu et al., 2007; Ickler, 2009; Wang, 2009; Wang and Zhang, 2012). Despite the rapid emergence of the s-commerce phenomenon (Shen, 2012), academic studies are still in early stages and scholars have only recently attempted to establish a standard definition of social commerce (Liang and Turban, 2011). By analysing more precisely the concept of social commerce, it is possible to identify a combination of social media and e-commerce. In this way, people have the possibility to purchase products or services and at the same time share information, experiences, and opinions with others (Liang et al., 2011; Jascanu et al., 2007; Wang, et al., 2015). More broadly, s-commerce is an extension of e-commerce (Liang and Turban, 2011) through which both consumers and retailers can obtain several benefits. If e-commerce can be considered as a static form of selling where people (as consumers and sellers) can buy and sell without interaction with each other, s-commerce is a way to share something that creates a relationship not only between consumers and retailers (B2C) during the shopping process but, in general, between humans $(\mathrm{H} 2 \mathrm{H})$. This particular interaction stimulates relational opportunities around the simple transactional exchange and could contribute to the system of social interactions. The social commerce process is a system of activities and relations that act together through the transactional and relational activities that affect the interacting actors. Within social commerce, people have the possibility to identify the products that are more suitable for their needs or also to ask for help from the community and to interact with others (Kim and Srivastana, 2007). In this way, people became active producers of content over the Internet (Ickler et al., 2009) and are no longer passive, as in the past. E-commerce integrated with s-commerce is useful in searching for products or information about products or sellers and sharing information, content, or recommendations through social media function is useful to interact with retailers and other involved actors. An s-commerce platform can be considered as a place where people can buy something with the intrinsic value related with the social aspect by which also the shopping process becomes social (Leitner and Grechening, 2007; Kim and Srivastava, 2007; Kang and Park, 2009; Shen, 2012). Social interaction has become the predominant element in the s-commerce process, and the creation of the relationship between people is now what drives the conversation: consumers are signalling the way that businesses must follow. People in general are increasingly familiarizing themselves with social media, and retailers within town centres cannot ignore this phenomenon. S-commerce, in its use of social media to permit people to share opinions, has changed the way people shop: "people have the power to share and make the world more open and connected" (Roblek et al., 2013). The purchase activity completes the process, but it is not always necessary in value creation, and retailers can improve their profit by attracting and maintaining customers through recommendations (Curthy and Zhang, 2011). An s-commerce platform can be considered as a virtual small village where people communicate and share information about products, services, prices, deals, opinions, and experiences, write comments on goods and services, create a shopping list to share with friends or other customers, and build relationships with retailers (Leitner and Grechening, 2007), consumers, and other people interested in the town centre retail. All in all, town-centre retailers could integrate their marketing strategy in a social way by connecting e-commerce with social media tools to create new opportunities in stakeholder involvement.

\section{Methodology}

To achieve the purpose of this paper, different methods were used. First of all, as presented in the previous paragraph, a literature review (Rowley and Slack, 2004) on town centre management and s- commerce is presented in order to identify the state of research by integrating the research with meanings and applications of social technologies to the management of a town centre. Furthermore, a particular research focus is presented by the identification of the concept of "belonging" as one of the relevant components of the attractiveness of the TCM. Effective experiences regarding TCM in a Swedish context are presented, showing the state-of-the-art methodologies during the studied period regarding Town Centre Management retailers' perception of the use of social commerce. Afterward, the emerging results by the specific experiences are faced with the current state of Swedish TCMs' websites. This match permits us to study the correlation between the wish of social integration expressed during the years of field research and the social activities actually carried out by Swedish TCM and retailers. During 2012 and 2013, a participant observation (Spradley and McCurdy, 1980; Spradley, 2016) was conducted and key informants were interviewed (DeWalt and DeWalt, 2011) to investigate social commerce from retailers and TCM in Stockholm, Västerås, Malmö, and Göteborg. In particular, associations of TCM such as City 
I Samverkan (the no-profit organization, the members are Stockholm city, property owners, trade, Stockholm public transport and the police as well as individual companies and organizations) and Svenska Stadskärnor (The Swedish Association of Town Centre Management) were selected. These research activities was repeated for a second time in 2015 and 2016 in order to verify eventual differences, and for a second time, the outcomes were correlated with the emergent results coming from the analysis of the TCM's website. Finally, from merging the literature and field experiences, an interpretation on the role of social commerce within the TCM attractiveness is presented.

\section{The analysis in Swedish context}

The reasons for choosing to analyse the Swedish context is twofold. The first reason is related to a period of visiting research at the Stockholm University, School of Business, within the Stockholm Programme of Place Branding. During this period, it was possible to create work relationships between the researcher and several TCM organizations and retailers in the major cities of Sweden, which was useful to conduct this research. The second reason is related to the high technology development in Sweden. This country is considered a global leader of innovation with a highly skilled labour force, sophisticated consumers, smooth business procedures, openness to international ownership, and a stable economy. More precisely, the European Innovation Scoreboard, an index published by the European Commission, in 2010 ranked Sweden as the leading country for innovation among EU member states. Reasons for this include a historic tradition of inventors, a commitment to gender equality, and a strong belief in the individual. In the 2016 the EU Commission released the Summary Innovation Index, which is a composite indicator based on the average innovation performance., Sweden is among the Innovation Leaders with innovation performance well above that of the EU average. Another element that guided the decision to use a Swedish context is related to the fact that Sweden has 10 million inhabitants, and $86 \%$ of these live within cities. A report (E-commerce in the Nordics Six-month report 2016 By Postnord) of online commerce in Nordic countries stated that six out of ten people in Nordic countries shopped online in the first six months of 2016. But, it was especially interesting that the largest percentage of online shoppers live in Sweden, where e-commerce has reached a significant level of maturity in relation of operators, competitors, infrastructure, and logistics. More precisely, in the first six months of 2016 in Sweden, 4.542 .000 consumers shopped online. The selection of cities is related to the dimension of these places. In particular, the highest percentage of Sweden population live in Stockholm, the capital, as well as in Göteborg (the second largest city in Sweden located in the West) and in Malmö (the third largest city located in the south of Sweden). Therefore, these regions were selected as being the most important zones of Sweden in relation to population and business retail activities. The city of Västerås was selected for intense activity in the revitalization of the town centre process. The principal organization of TCM in Sweden originated there, and this guided the development of the Swedish town centre. The Swedish Association of Town Centre Management (Svenska Stadskärnor), founded in 1993, is a national association with 140 member organizations from both public and private sectors, such as local communities, town centre management organisations, property owners, retailers, architects, and national public authorities. The principal activities aim to exchange experiences of town centre management and town centre development, including coordinating conferences, seminars, and study tours and initiating studies and taking part in the official debates in the field of town centres.

\section{Results}

From the analysis of the context, it is apparent that town centre management was developed in order to face challenges within a town centre, and one of the principal goals is to address the cooperation among all people that work and live within the town centre. In particular, the observation and informal interviews conducted within a Swedish town centre showed that most retailers and managers work together to increase the town centre attractiveness in order to combine out-of-town shopping with a dynamic inner city. Offering an attractive environment for shopping with a pleasant, compact shopping area is one of the most difficult challenges. Moreover, Town centre management is aware of the need to implement social technologies to engage all active parts within the town centre. But, there has not yet been any implementation of a social platform that is able to create a virtual place where people can share information, products, services, and experiences. This important insight was integrated with the analysis of the Town centre website in order to verify whether there is a connection with social media and integration with online commerce. Inside the website analysed, there is a connection with the principal social media (Facebook, Twitter, and Istangram), but there is not a connection with several forms of online commerce (Table 1). In particular, what emerged from the website analysis is that the content shared within social media are introduced by the management of the town centre with very less interactions with people. So, the social media are only used to post something related to events. There are much less posts related to shopping and retail activities that are shared within social media. In particular, only on the Västerås Citysamverkan website is there a specific part that identifies all retailers placed within the town centre. Within Stockhom City I Samverkan, there is a specific retail guide that identifies the principal zone of shopping not only in Stockholm but also in Gothenburg and Malmo, but there is no specific focus about retailers present within the town centre. 


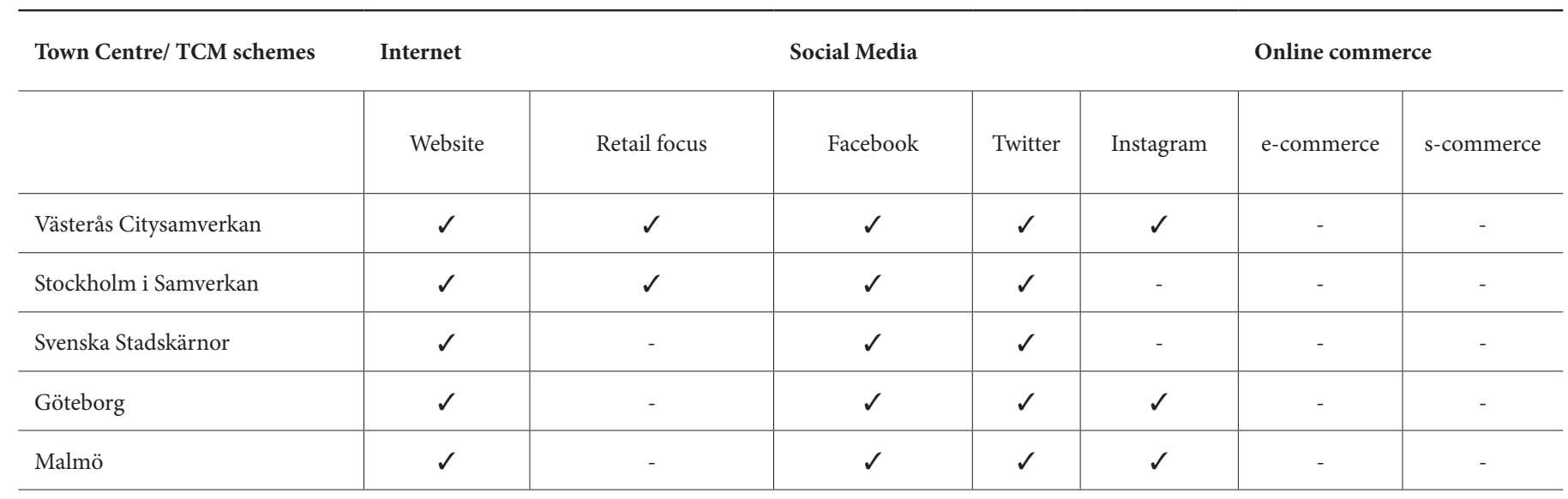

Source. Authors' elaboration

\section{Discussion}

Literature and practical experiences focused on participant observation help to speculate on the role of s-commerce within TCM activity and, in particular, within the TCM attractiveness. Empirical and quantitative studies could explain relations and correlations between agents and interactive factors between TCM and different stakeholders, and the following qualitative approach represents a contribution to express the system of components of attractiveness about the TCM in relation to the social commerce nature, focusing on the stimulation of the sense of "belonging" as its main component of attractiveness of TCM's demand-that is, customers of retailers, visitors, investors, stakeholders.

\section{Social commerce and retailers}

Through the use of social networking platforms, online purchases are the only formal conclusion of a long process of socialization, communication, and exchange of information that goes beyond the single purchase. S-commerce is for retailers a system of auto-generated services that allow retailers to improve (or destroy) the whole reputation of the store, the positioning of the value offers that increase (or reduce) the distances between customers. Through this kind of online commerce, consumers can conduct a transaction directly with sellers without having contact with the physical store (Terzi, 2011); this occurs after the exchange of information with the retailer. Sometimes, the community could contribute to increasing the shopping experience by giving advice about products and services and, in some platforms, giving grades and evaluations about the services, providing information regarding the relationships with the retailer, quality of the product, and suggestions about new products. For the single retailer, social commerce is able to increase the opportunity, as stated by e-commerce in the past, and could contribute to building positioning of a retail offering, to increase the affection in the store brand and, sometimes, for the physical store. In that case, the affection in the store is generated by the social relationships between store employees and community involved in the social e-commerce. The online dialogue and the stimulated relationship could continue off line.
Social commerce and sales within the TCM

Considering the TCM experience, social commerce is functional for retailers included in the TCM area, but at the same time, it is useful in particular for retailers who are able to use the tool to establish relationships with the virtual community that follows a path of relationship "materialization" with the real world (i.e., retail offering) of the TCM that represent a system of place offering, including the retail offering. The TCM presents strengths based on the system of offering made by public and private partnerships that include different territory stakeholders - retailers included - and for this reason, it is difficult to generate an increase of sales caused by the variety of the offering; probably, the s-commerce related to the TCM loses relevance in turnover increasing for the single retailer and assumes new opportunities and perspectives. The meaning behind social commerce, within the theoretical background expressed, could affect new collective lines, representing, for instance, a virtual "outlet centre" in which it is possible to provide offerings out of markets, discounts, sales, and special prices. The new collections and services could then be distributed directly in store; at the same time, social commerce could server several purposes, such as solidarity or communicationfor example, collecting the contributions of associated retailers in an e-commerce site that sells products and services for a variety of non-profit economic activities with the goal to increase town centre popularity. It could likewise be used to sell rare, antique, or precious products to users who are physically very distant from downtown streets. That strategy could stimulate discussion, word of mouth, and curiosity for a place offering and could be useful both for TCM (i.e., increasing the number of visitors) and for the single retailers because of the reduction of inventories that increase sales and improve the opportunity to obtain sales directly in the store.

\section{Social commerce and TCM attractiveness}

Less is known about the attractiveness of the whole TCM system; in general, the attractiveness is studied from a place-marketing perspective, following the demand-driven view (Kotler, 1993; Gertner, 2011). In this work, a supply-driven view of attractiveness is proposed, 
following the principles that regulates the place-branding activities (Kavaratis et al. 2015; Gertner, 2011); this is due to the necessity to use social commerce to stimulate town centre management positioning and, in particular, the sense of belonging by the demand side (i.e., customers, visitors and different TCM stakeholders). Different points of view are able to represent a multiplicity of processes that affect attractiveness. A correlation between attractiveness and TCM is presented below, and the perception by the users side is represented by a mix of stimuli that come from the town centre value proposition. The capability to attract stakeholders could both be the result of a marketing strategy or the effects of the place image (Govers et al. 2009), and for this reason, the attractiveness is linked with the sense of belonging and with the experiences of the subjects that interact with the TCM organization. Many authors study the role of experience in the city centre and, in particular, within TCMs (Hart et al., 2013); it is possible to assume that the attractiveness in the TCM could be represented by the result of a system of stimuli and perceptions of the subject involved based on experiences and sense of belonging.

Figure 1. System of experiences and sense of belonging representing the attractiveness in the TCM

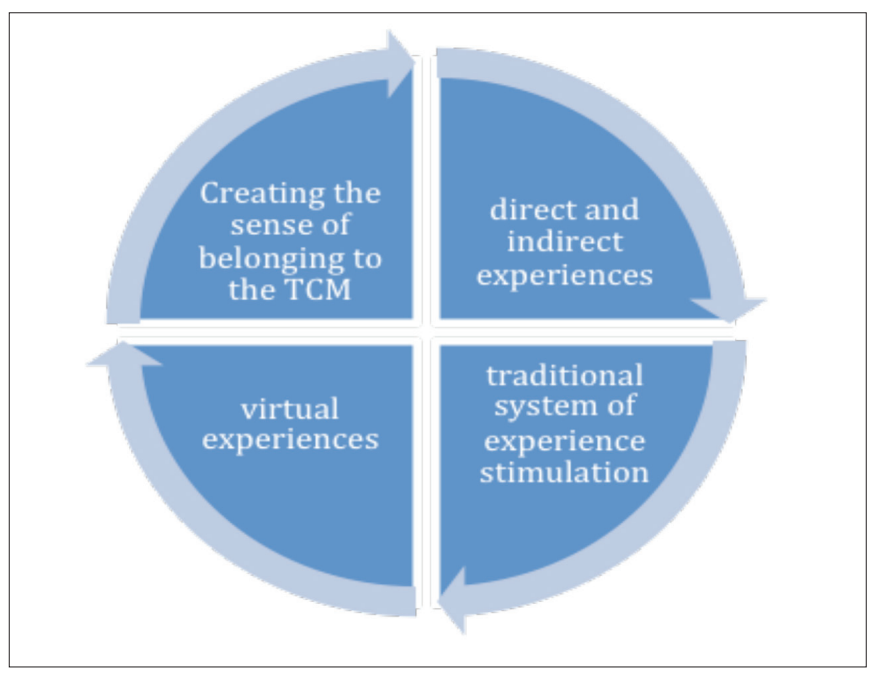

Source: Authors' elaboration

In a simplification of the mix of experiences and sensations that define attractiveness (see Figure 1), it is possible to represent the direct and indirect - real and virtual - experiences and the sense of belonging that could be interests the users side.

-Direct and indirect experiences. These represent the experienced visits, life experiences, and impressions within the TCM area. The indirect experiences come from the system of indirect stimuli made by perceptions of the third parties' experiences, i.e., tales, movies, word of mouth, travel experiences;

-Traditional system of experience stimulation. In this category, it is possible to consider the system of experiences that emerge by the place organization and by the organized offering of the place, improved eventually by the communication plans and particular events;
-Virtual experiences. This includes stimulating experiences by virtual tours using advanced technology online, webinars, videos, online reputation that in particular are able to directly involve the single subject interested in the town centre experience.

-Creating the sense of belonging to the TCM. Many opportunities are able to create the sense of belonging-for instance, participation in TCM activities; it is possible to consider the direct experiences to stimulate the sense of belonging as well as the indirect (or online) experience. In particular, the first are experienced directly within the TCM area, while the second need to be supported by the virtual community and, in this case, by social network activity. In particular, social commerce could be an opportunity to share opinions and advices between members of the same TCM website.

Social commerce represents a technological opportunity that is able to integrate and merge the concept of e-commerce with social network relationships that come from the website. By looking for the nature of the TCM, it is possible to argue that the purpose of this advanced method goes beyond the mere action to sell the integrated offering of the retailers involved in the TCM. First of all, the TCM goal is not only sales optimization of aggregated retailers, but as the literature sustains, the whole TCM has the aim to revitalize the city centre. For this reason, the function of sales inside a social commerce website could represent a secondary activity-a marginal function that stimulates the contacts between the interested subjects to the website. The resources and information exchange - for example, between the public and private government sharing projects, opportunities, revitalization activities, events design and management, comments, point of views, feedbacks about the tenant mix of the retailers, and the communication of opportunities - about the TCM in an open platform are relevant. Open platform sharing permits the actors - public, private, citizens, visitors, and a multiplicity of stakeholders as well - to express opinions and present points of view, insights, and ideas inside and around the TCM organization. It is possible to assume that social commerce in TCM could substitute classical social network pages because in the classical social network pages, the resources exchange is focused only on information exchange; in social commerce websites, e-commerce and social activities are interactive, and for this reason, they are able to be one part of the other and link different goals and multiplicity of strengths. By linking experiences with literature contributions, particular relations emerge by the contacts between users and social commerce websites within the TCM. The s-commerce process develops in three stages of shopping (i.e., social, e-commerce, purchase). The s-commerce framework gives different results and perceptions to the user depending on the relevance attributed to the three stages of shopping. Regarding the three stages of s-commerce, it is possible to argue that users interested by the purchase activity probably presents a first interest to the single product/ service purchase with a limited interest to the relationship with the supplier, community, and TCM activity. In that case, the interest in the purchase is the unique element that brings the user to frequent the website. Subjects interested in the e-commerce activity could be, in general, interested in the whole e-commerce activity of social 
commerce, and the user could represent a stable customer who is interested by the whole e-commerce offering. They could also be, in part, stimulated by the social activity on the portal. A first link between the whole TCM offering is possible. It is possible to consider the interest in value offering of the s-commerce activity in TCM realized by reliability, reputation, and positioning. The interest for the social activity is a signal of interest for the community of the TCM, and the sense of belonging is much more marked. In that case, a system of elements is emerging and the exchange of resources, loyalty, and information emerge. In that case, the subject could be interested by the system of relationships and value perceived because the relational level is up to the utility function of the web site. It is possible to assume that users are interested in the value co-creation, participation, and belonging to the value proposition. In the table below the relation between the three stages of s-commerce and involvement of the user.

Table n. 2. Relation between three stages of s-commerce and user involvement

\begin{tabular}{ll}
\hline $\begin{array}{l}\text { The three stages of } \\
\text { s-commerce order }\end{array}$ & Approach by demand side \\
\hline $\begin{array}{l}\text { Purchase - e-commerce } \\
\text { - sharing }\end{array}$ & Interested by the product/service purchase \\
\hline $\begin{array}{l}\text { E-commerce - purchase } \\
\text { - sharing }\end{array}$ & $\begin{array}{l}\text { Interested by the value offering (reliability, } \\
\text { reputation, positioning) }\end{array}$ \\
\hline $\begin{array}{l}\text { Sharing - e- commerce - } \\
\text { purchase }\end{array}$ & $\begin{array}{l}\text { Interested by the value co-creation, } \\
\text { participation, and belonging to the value } \\
\text { proposition }\end{array}$ \\
\hline
\end{tabular}

Source: Authors' elaboration

\section{Conclusions}

The role of social commerce in TCM depends on different factors, including the positioning of the TCM, the value offering online and offline, the value in use of the website, and the perceptions of the users involved in the value offering. The result that comes from the s-commerce activity is always the synthesis of a multiplicity of stimuli that only partially is possible to regulate. Sure, the effects of a s-commerce strategy applied to the TCM is always a system of results that integrates both online and off-line activities. An s-commerce platform is a functional tool that represents an opportunity to manage the real life of the TCM; this is its first goal. The contents of the social activity need to be generated by the vivacity of the real community, and the on-line commerce opportunities are linked with a systematic activity of retailers' value propositions that cannot be, simply, the collection of individual value propositions. For this reason, each retailer or stakeholder interested in TCM s-commerce must be connected in the whole TCM strategy. This is because real people are behind the technologies, and for this reason, it is possible to be part of (or to belong to) the systems made by people. The Swedish field experiences and data represent a situation that has not changed in the past years. The observations present interest in e-commerce and s-commerce use by retailers but, anyhow, no investments in this field are in evidence. An analysis of Swedish websites unveiled that there is no implementation of a social platform that seeks to increase the attractiveness of a town centre. In particular, retailers have created their own websites (or a Facebook page) to communicate with their customers. But, there is currently no cooperation with TCM to create a TCM social platform. It is possible to argue that large difficulties associated with time and economic resources emerged, including management of online and offline activities, standardization of information systems, and shared marketing strategies. Generally, in the medium and long run, the public-private partnership (with regards to TCM) is centered on offline activities; the different cases underline the difficulties of partnerships and, in particular, public-private partnerships. Online activities are considered as a residual stuff, though in TCM activities, different actors elevate its relevance. Sometimes, online activities are used in communication and information, while e-commerce activities are singularly developed by each retailer in specific and individual websites and are not considered as a systemic opportunity on the TCM website. A triple change of paradigm emerges by different sides, including TCM management and demand (including visitors and consumers in TCM). The retailers believe new opportunities could come from the s-commerce approach to the TCM. In any case, the s-commerce activity could increase the TCM and single retailer awareness because of the exchange of relationships between the different actors in the system. From the TCM management side, the relevance of scommerce is represented by different opportunities, including consolidation of the positioning in relation to the TCM activities. From the demand side, the implementation of an s-commerce platform could be useful to increase confidence and sense of belonging with the TCM's philosophy, the demand, and different stakeholders. In particular, through a social commerce platform, people within the town centre have the possibility to try new kinds of experiences and to become an active protagonist in the creation of the strategy and actions of TCM. In this way, TCM could become a social community where people (i.e., citizens, tourists, investors, public and private entities) have the possibility to share any kind of experience and be involved in the administration of the Town Centre in order to increase the attractiveness of the place. Further studies could specifically research the relationships between s-commerce and developing opportunities in TCM. In particular, future studies should research possible improvements to managing positioning and boosting a sense of belonging as well as determining online and offline effects.

\section{References}

Baron, M., Salmelin, B., Mention, A. L., Torkkeli, M., Aas, T. H., Pedersen, P. E., and Paasi, J. (2016). Open innovation and territory. Open Innovation: A Multifaceted Perspective: Part I pp. 241-272.

Caboni, F., and Bruni, R. (2015). On-line Commerce and Town Centre Retailers' Experience. International Journal of Marketing Studies, Vol.7 No.6, pp.14. http://dx.doi.org/10.5539/ijms.v7n6p14

Caragliu, A., Del Bo, C., and Nijkamp, P. (2011). Smart cities in Europe. Journal of urban technology, Vol 18 No.2, pp. 65-82. http://dx.doi. org/10.1080/10630732.2011.601117 
Chang, B.J. (2012). Channel strategies, product types, and performance in the us retail industry. International Journal of Electronic Marketing and Retailing, Vol. 5 No. 2, pp.110-127. http://dx.doi. org/10.1504/IJEMR.2012.051030

Chourabi, H., Nam, T., Walker, S., Gil-Garcia, J. R., Mellouli, S., Nahon, K., and Scholl, H. J. (2012). Understanding smart cities: An integrative framework, System Science (HICSS), 2012 45th Hawaii International Conference.pp. 2289-2297. IEEE. http://dx.doi.org/10.1109/ HICSS.2012.615

Coca-Stefaniak, A. (2014). Place branding and city centre management: Exploring international parallels in research and practice. Journal of Urban Regeneration \& Renewal, Vol 7 No.4, pp.363-369.

Curty, R. G., and Zhang, P. (2011). Social commerce: Looking back and forward. Proceedings of the American Society for Information Science and Technology, Vol 48 No.1, pp.1-10. http://dx.doi. org/10.1002/meet.2011.14504801096

DeWalt, K. M., and DeWalt, B. R. (2011). Participant observation: A guide for fieldworkers. Rowman Altamira.

Gertner, D. (2011). Unfolding and configuring two decades of research and publications on place marketing and place branding. Place Branding and Public Diplomacy, Vol 7 No. 2, 91-106. http://dx.doi. org/10.1057/pb.2011.7

Govers, R., and Go, F. (2009). Place branding-glocal, physical and virtual identities constructed, imagined or experienced, Basingstoke, Hampshire, UK: Palgrave Macmillan

Hart, C., Stachow, G., and Cadogan, J. W. (2013). Conceptualising town centre image and the customer experience. Journal of Marketing Management. Vol 29 No.15-16, pp.1753-1781. http://dx.doi.org/10.10 80/0267257X.2013.800900

Ickler, H., Schülke, S., Wilfling, S., and Baumöl, U., (2009). New in E-Commerce: How Social Commerce Influences the Customer Process. In Proceedings of the 5th National Conference on Computing and Information Technology, NCCIT (pp. 51-57).

Izquierdo-Yusta, A. and Newell, S.J. (2011). Consumer beliefs and motivations that influence repeat online purchases. International Journal of Electronic Marketing and Retailing, Vol. 4 No. 4, pp.270292. http://dx.doi.org/10.1504/IJEMR.2011.045611

Jascanu, N., Jascanu, V., and Nicolau, F. (2007). A new approach to E-commerce multi-agent systems. The Annals of "Dunarea De Jos" University of Galati: Fascicle III Electrotechnics, Electronics, Automatic Control and Informatics, pp.8-11.

Kang, Y. R., and Park, C. (2009). Acceptance factors of social shopping, In Advanced Communication Technology, 2009. ICACT 2009. 11th International Conference on Vol. 3, pp. 2155-2159. IEEE.
Kavaratzis, M., Warnaby, G., and Ashworth, G. J. (2015). Rethinking place branding, Springer International Publishing Switzerland.

Kim, Y., and Srivastava, J. (2007). Impact of social influence in e-commerce decision making. In Proceedings of the ninth international conference on Electronic commerce (pp. 293-302). ACM. http://dx.doi. org/10.1145/1282100.1282157

Kotler, P. (1993), Haider, DH; Rein, I. Marketing places. Free Press, New York

Leitner, P., and Grechenig, T. (2007). Community driven commerce: Design of an integrated framework for social shopping. IADIS International Conference e-Commerce p. 4.

Liang, T. P., and Turban, E. (2011). Introduction to the special issue social commerce: a research framework for social commerce. International Journal of Electronic Commerce, Vol 16 No 2, pp.5- 14. http:// dx.doi.org/10.2753/JEC1086-4415160201

Liang, T. P., Ho, Y. T., Li, Y. W. and Turban, E. (2011). What drives social commerce: the role of social support and relationship quality. International Journal of Electronic Commerce, Vol 16 No.2, pp.69-90. http://dx.doi.org/10.2753/JEC1086-4415160204

Musterd, S. and Murie, A. (2010). Making competitive cities. United Kingdom: Blackwell.

Oc, T., and Tiesdell, S. (1998). City centre management and safer city centres: approaches in Coventry and Nottingham. Cities, Vol 15 No.2, pp.85-103. http://dx.doi.org/10.1016/S0264-2751(97)10016-6

Rezaei, S., and Ismail, W. K. W. (2014). Examining online channel selection behavior among social media shoppers: a PLS analysis. International Journal of Electronic Marketing and Retailing, Vol 6 No.1, pp.28-51. http://dx.doi.org/10.1504/IJEMR.2014.064876

Roblek, V., Meško, M., and Bertoncelj, A. (2013). Social Media, Organizational Changes and Added Value in Knowledge-Based Industries. Proceedings of the 1st AARESOC International Conference on Business \& Management.

Rowley, J. and Slack, F. (2004). Conducting a literature review. Management Research News, Vol 27 No.6, pp. 31-39. http://dx.doi. org/10.1108/01409170410784185

Shapiro, J. M. (2006). Smart cities: quality of life, productivity, and the growth effects of human capital. The review of economics and statistics, Vol 88 No2, pp.324-335. http://dx.doi.org/10.1162/rest.88.2.324

Shen, J. (2012). Social comparison, social presence, and enjoyment in the acceptance of social shopping websites. Journal of Electronic Commerce Research, Vol 13 No.3.

Spradley, J. P. (2016). Participant observation. Waveland Press. 
Spradley, J. P. and McCurdy, D. W. (1980). Anthropology, the cultural perspective. John Wiley \& Sons.

Terzi, N. (2011). The impact of e-commerce on international trade and employment. Procedia-Social and Behavioral Sciences, Vol 24 pp.745-753. http://dx.doi.org/10.1016/j.sbspro.2011.09.010

Wang, C. (2009). Linking Shopping and Social Networking: Approaches to Social Shopping. 15th Americas Conference on Information Systems (AMCIS), San Diego, CA.
Wang, C. and Zhang, P. (2012). The Evolution of Social Commerce: The People, Management, Technology, and Information Dimensions. Communications of the Association for Information Systems, Vol 31 No.5, pp.1-23.

Wang, T., Yeh, R. K. J. and Yen, D. C. (2015). The Influence of Customer Identification on Online Usage and Purchasing Behaviors in Social Commerce. International Journal of Human-Computer Interaction, Vol. 31No.11, pp. 805-814. http://dx.doi.org/10.1080/104473 18.2015.1067481 